\title{
Inoculant Effects on Alfalfa Silage: In Vitro Gas and Volatile Fatty Acid Production
}

\author{
R. E. Muck, ${ }^{\star 1}$ I. Filya, $\dagger$ and F. E. Contreras-Goveał \\ *USDA, Agricultural Research Service, US Dairy Forage Research Center, Madison, WI 53706 \\ †Department of Animal Science, Faculty of Agriculture, Uludag University, 16059 Bursa, Turkey \\ ‡Department of Agronomy, University of Wisconsin, Madison 53706
}

\section{ABSTRACT}

Alfalfa silages from 2 similar trials were analyzed for in vitro ruminal gas production. In both trials, there were 15 treatments: alfalfa treated at ensiling with 1 of 14 lactic acid bacterial inoculants or untreated alfalfa. First-cut (477 g of dry matter/kg) and second-cut (393 $\mathrm{g}$ of dry matter $/ \mathrm{kg}$ ) alfalfa were ensiled in glass jars for a minimum of $35 \mathrm{~d}$ at room temperature $\left(\sim 22^{\circ} \mathrm{C}\right)$. At opening, a portion of each silage was wet-ground with a mixer. Each silage was then assessed for in vitro ruminal gas production in 3 replicate runs with the wet-ground silage, 1 on the fresh silage and 2 on frozen and thawed silage. In vitro gas production was measured in $160-\mathrm{mL}$ sealed serum vials incubated at $39^{\circ} \mathrm{C}$. One gram of silage was incubated with $17.1 \mathrm{~mL}$ of nutrient solution, $0.9 \mathrm{~mL}$ of reducing solution, and $12 \mathrm{~mL}$ of ruminal inoculum (1:2 vol/vol mixture of rumen fluid and buffer). Gas production was measured manually by using a pressure gauge at $3,6,9,24,48$, and $96 \mathrm{~h}$. At $96 \mathrm{~h}$, the rumen fluid was analyzed for $\mathrm{pH}$ and volatile fatty acids. In the 2 trials, the untreated control silage produced either numerically the highest or one of the highest levels of gas production per unit of dry matter incubated. In first-cut silage, 9 of the inoculant treatments at $9 \mathrm{~h}$ and 4 treatments at $96 \mathrm{~h}$ had reduced gas production compared with the control. In secondcut silage, 10 inoculant treatments at both 9 and $96 \mathrm{~h}$ had reduced gas production compared with the control. Furthermore, in first-cut silage, the fraction of total gas production at 3,6 , and $9 \mathrm{~h}$ was numerically the highest for the control, and only 4 treatments were not significantly lower than the control at $9 \mathrm{~h}$. In second-cut silage, 2 of 14 inoculated treatments produced faster fractional rates of gas production than the control, but most inoculated treatments had numerically slower fractional rates (4 significant) in the first $9 \mathrm{~h}$. The in vitro fermented wet-ground control silages had one of the high-

Received December 21, 2006.

Accepted June 30, 2007.

${ }^{1}$ Corresponding author: richard.muck@ars.usda.gov est acetate:propionate ratios in both trials, significantly higher than 12 and 8 of the inoculated treatments in first- and second-cut silage, respectively. The response in acetate:propionate ratio in both cuts was similar, even though the control silage was highest in lactic acid in one trial and lowest in the other. Overall, inoculation of crops at ensiling appears to affect in vitro ruminal fermentation of wet-ground silages, even in the absence of large effects during silage fermentation.

Key words: alfalfa silage, in vitro fermentation, lactic acid bacteria

\section{INTRODUCTION}

The application of lactic acid bacteria (LAB) to crops at ensiling to improve silage quality is a common practice in the United States and Europe. Homofermentative LAB such as Lactobacillus plantarum, Enterococcus faecium, and Pediococcus spp. are used, with the goal of providing a faster fermentation, lower final $\mathrm{pH}$ values, raised lactate:acetate ratios, lower ethanol and ammonia nitrogen concentrations, and improved DM recovery (Weinberg and Muck, 1996). Recently, a heterofermentative LAB inoculant species, Lactobacillus buchneri, has become available commercially and produces high concentrations of acetic acid in silage, which inhibit fungi and thus preserve silages susceptible to spoilage upon exposure to air (Weinberg et al., 2002; Filya, 2003a,b).

Although the primary function of LAB has been to improve the preservation of crops in the silo, homofermentative LAB inoculants in particular have been shown in various studies to improve milk yield, gain, and feed efficiency (Kung et al., 2003). In a summary of 36 studies, Kung and Muck (1997) reported that milk yield was increased in $47 \%$ of the studies when inoculated silage was fed, compared with untreated silage. The average increase in milk production for those studies in which the inoculant enhanced milk yield was 1.4 $\mathrm{kg} /$ cow per d (Kung and Muck, 1997). Some LAB strains have shown an even more consistent effect on milk yield. Kung et al. (2003) reported that L. plantarum 
MTD1 had a positive effect on milk yield in $83 \%$ of the 12 studies reviewed.

Although animal trials have shown improved animal performance from feeding inoculated silages, there are still questions regarding how relatively minor shifts in silage fermentation can produce significant changes in animal performance. Weinberg and Muck (1996) suggested that microbial inoculants may produce a probiotic effect in the rumen, the mechanism of which is unknown. This suggestion of a probiotic effect arises from the magnitudes of the effects that have been observed in various studies as well as from multiple reported studies (e.g., Gordon, 1989; Steen et al., 1989; Kung et al., 1993) in which animal performance was improved when an inoculated silage was fed, even though the inoculant failed to significantly alter silage fermentation compared with fermentation in an untreated control silage.

Various in vitro and in sacco techniques have been used to help predict the digestibility of feedstuffs, and these should be helpful in predicting whether there should be an animal response to silage inoculation. Routine in vitro techniques, such as those by Tilley and Terry (1963) and Goering and Van Soest (1970), measure the residue after a given incubation time in rumen fluid. Rates of fermentation with time can be generated, but with considerable effort. Fermentation rates are easier to generate with in sacco techniques. However, various in vitro gas production techniques have been developed (e.g., Theodorou et al., 1994; Schofield and Pell, 1995; Rymer et al., 1998). These studies have shown the value of measuring gas production as a means of estimating the rate and extent of in vitro rumen fermentation. Furthermore, the VFA produced by ruminal microorganisms during in vitro fermentation should be stoichiometrically related to gas production (Blümmel et al., 1997).

If the LAB in silages are having a direct effect on rumen fermentation, then performing an in vitro procedure with a dried sample may mask the effects occurring in an in vivo situation. Calabrò et al. (2001) recently reported that in vitro gas production was higher with fresh silages $(228 \mathrm{~mL} / \mathrm{g})$ than with silages dried at $65^{\circ} \mathrm{C}(162 \mathrm{~mL} / \mathrm{g})$. Total VFA produced in the in vitro incubations tended to be higher in the fresh silages, and the acetate:propionate ratio was higher from incubating fresh silages. Lee et al. (2002) compared the in vitro ruminal fermentation of freeze-dried and 1-mm ground grass with grass frozen, thawed, and cut into 10-mm lengths. Gas production was higher in this case with the dried samples, but the acetate:propionate ratio was higher in the frozen and thawed grass. These results indicate that undried samples ferment differently in in vitro systems than do dried samples.
Because we do not know what an inoculant does to alter ruminant digestion and utilization of a silage, it may be important to measure in vitro digestibility on undried silages to more closely mimic conditions in the cow.

Previously, we reported on 2 alfalfa silage trials comparing 14 inoculant treatments with an untreated control (Filya et al., 2007). In first-cut alfalfa, silage fermentation was substantially affected by the inoculant treatments [with $\mathrm{pH}$ values for 13 of the 14 treatments below that of the untreated control $(P<0.05)$, and a maximum difference from the control of $0.75 \mathrm{pH}$ units]. However, there were no significant effects on in vitro true DM digestibility (IVTDMD) at $48 \mathrm{~h}$ with freezedried samples. In second-cut alfalfa, the inoculant treatments had considerably more modest effects on silage fermentation. Only 5 inoculant treatments had $\mathrm{pH}$ values significantly below that of the untreated control; the maximum difference was $0.13 \mathrm{pH}$ units. Significant treatment effects on IVTDMD were observed but were due to reductions in IVTDMD by some inoculant treatments relative to the control. The objectives of the study reported here were to compare the effects of inoculant treatment on the rate and extent of in vitro gas production by using undried samples from these 2 trials, and to compare these in vitro results with results of the previously reported IVTDMD values.

\section{MATERIALS AND METHODS}

\section{Silage Preparation}

In 2003, alfalfa was ensiled in 2 trials [first cut ( 477 $\mathrm{g}$ of $\mathrm{DM} / \mathrm{kg}$ ) and second cut (393 $\mathrm{g}$ of $\mathrm{DM} / \mathrm{kg}$ )] on June 9 and July 2, respectively]. In both trials, alfalfa was harvested with standard field equipment (mower-conditioner, forage harvester) without inoculation. Approximately $40 \mathrm{~kg}$ was collected from a load of alfalfa after being dumped during the process of filling a field-scale silo. The chopped alfalfa was ensiled in 1.0- and 0.5-L anaerobic glass jars (Weck, Wher-Oftlingen, Germany), respectively, at a density of $500 \mathrm{~g} / \mathrm{L}$. Each trial had 15 treatments (uninoculated control and 14 inoculants), with 4 silos per treatment. Eight inoculants were commercial products, and the others were single strains provided by 2 companies (Table 1 ). All inoculants were applied at a rate of $1.0 \times 10^{6} \mathrm{cfu} / \mathrm{g}$ of crop as fed (not label rates) to help ensure the domination of fermentation. All inoculants were diluted with distilled water so that they were all applied at the same rate $(10 \mathrm{~g}$ of solution $/ \mathrm{kg}$ of crop as fed). The control received $10 \mathrm{~g}$ of water/kg of crop as fed. The amount of chopped alfalfa for a given silo was weighed out by taking approximately 6 random grabs from the collected forage, sprayed with the appropriate inoculant solution with a plant sprayer (one sprayer for each treatment), mixed 
Table 1. Inoculants used in the experiments

\begin{tabular}{lll}
\hline Number $^{1}$ & \multicolumn{1}{c}{ Inoculant } & \multicolumn{1}{c}{ Source } \\
\hline 1 & Lactobacillus buchneri (Pioneer 11A44) & Pioneer Hi-Bred International Inc., Des Moines, IA \\
2 & L. buchneri (Biotal) & Biotal Canada Limited, Calgary, Alberta, Canada \\
3 & Lactobacillus plantarum and Enterococcus faecium (Pioneer 1174) & Pioneer Hi-Bred International Inc., Des Moines, IA \\
4 & L. plantarum and Pediococcus cerevisiae (Biomate LP/PC) & Chr. Hansen Biosystems, Milwaukee, WI \\
5 & L. plantarum (Biomax 5) & Chr. Hansen Biosystems, Milwaukee, WI \\
6 & Pediococcus pentosaceus and Propionibacterium jensenii (Biotal Plus) & Biotal Canada Limited, Calgary, Alberta, Canada \\
7 & E. faecium, L. plantarum, and Pediococcus spp. (H/M Plus) & Medipharm USA, Des Moines, IA \\
8 & L. plantarum MTDI (Ecosyl) & Ecosyl, Yorkshire, UK \\
9 & E. faecium C (Agri-King) & Agri-King, Fulton, IL \\
10 & E. faecium Q (Agri-King) & Agri-King, Fulton, IL \\
11 & Lactobacillus pentosus (Agri-King) & Agri-King, Fulton, IL \\
12 & L. plantarum (Agri-King) & Agri-King, Fulton, IL \\
13 & P. pentosaceus (Agri-King) & Agri-King, Fulton, IL \\
14 & P. pentosaceus (Ecosyl) & Ecosyl, Yorkshire, UK \\
\hline
\end{tabular}

${ }^{1}$ Inoculants 1 to 8 are commercially marketed.

by hand, and placed into the silo by hand with periodic tamping. Equipment coming in contact with the treated alfalfa was washed and wiped with ethanol between treatments to prevent cross-contamination. Over the course of filling the silos for all treatments, 4 samples of untreated chopped alfalfa were taken for analysis of initial characteristics, and all inoculant solutions were analyzed for LAB counts. Silos were stored for 35 and $47 \mathrm{~d}$, respectively, at room temperature $\left(\sim 22^{\circ} \mathrm{C}\right)$.

\section{In Vitro Gas Production}

At the opening of the silos, a portion of the silage was removed and wet-ground for approximately $20 \mathrm{~s}$ in a Büchi B-400 mixer (Büchi, Flawil, Switzerland) to a particle size of approximately 1 to $4 \mathrm{~mm}$. The ground silage was divided into 2 portions; one was kept in the refrigerator $\left(4^{\circ} \mathrm{C}\right)$, and the other was frozen at $-20^{\circ} \mathrm{C}$. Both portions were analyzed for in vitro gas production. In vitro analysis was performed on the refrigerated silage within $3 \mathrm{~d}$ of silo opening, with one run containing one replicate of all 60 silages from that trial. Later, 2 in vitro runs per trial were performed on the frozen silages, with one replicate of all 60 silages per run.

For each run, $1.0 \mathrm{~g}$ of wet-ground silage from each silo was weighed, placed in a $160-\mathrm{mL}$ serum bottle (Wheaton, Millville, NJ), and kept in a refrigerator overnight. The in vitro analysis and the preparation of the ruminal inoculum followed the procedures described by Weimer et al. (2005). On the day of inoculation, $17.1 \mathrm{~mL}$ of the Goering and Van Soest (1970) buffer was added to each bottle, and each bottle was placed in a water bath $\left(39^{\circ} \mathrm{C}\right)$, connected to a manifold, and continuously purged with $\mathrm{CO}_{2}$. After $30 \mathrm{~min}, 0.9 \mathrm{~mL}$ of reducing solution $(6.25 \mathrm{~g} / \mathrm{L}$ each of $\mathrm{Cys} \mathrm{HCl}$ and $\mathrm{Na}_{2} \mathrm{~S} \cdot 9 \mathrm{H}_{2} \mathrm{O}$ ) was added to each bottle, and the bottles were capped and placed in a warm room $\left(39^{\circ} \mathrm{C}\right)$ for 45 min. Rumen fluid was collected from 2 lactating, rumen- cannulated dairy cows in the morning. The cows were fed with a TMR diet that contained $30 \%$ alfalfa silage, $30 \%$ corn silage, $30 \%$ corn grain, and $10 \%$ soybean meal, plus supplemental vitamins and minerals. Rumen fluid from the 2 cows was combined, filtered through 4 layers cheesecloth, and mixed (1:2 vol/vol) with a buffer-mineral solution, with continuous bubbling of $\mathrm{CO}_{2}$. After samples were reduced, each bottle was tared before adding inoculum $(12 \mathrm{~mL})$ and was weighed immediately thereafter to measure the actual amount of inoculum added to each bottle. The bottles were capped with butyl rubber stoppers, sealed with aluminum crimps, and stored at $39^{\circ} \mathrm{C}$. Gas pressure was measured at $3,6,9$, 24,48 , and $96 \mathrm{~h}$ with a digital pressure gauge (model SEDPGB0015PG5, SenSym, Milpitas, CA) and gently swirled to mix the material each time. Raw gas production in each bottle was calculated based on pressure times a calibration factor obtained by measuring the equilibrated increase in pressure from injecting known volumes of $\mathrm{CO}_{2}$ into bottles with buffer, reducing solution, and ruminal inoculum. The raw gas production values from each run were adjusted by subtracting gas production from blank bottles (buffer, reducing solution, and ruminal inoculum; 4 per run) and then adjusted proportionally by using gas production from a dried alfalfa standard (2 samples per run) based on prior analyses of that alfalfa.

At $96 \mathrm{~h}$, the serum bottles were opened. The contents were analyzed for $\mathrm{pH}$ and VFA. The VFA were determined by HPLC with a refractive index detector (Muck and Dickerson, 1988). The HPLC system consisted of a Shimadzu system controller (SCL-10A), pump (LC10AT), and refractive index detector (RID-6A; Shimadzu Corporation, Kyoto, Japan) with a Bio-Rad Aminex HPX-87H column (Bio-Rad Laboratories, Hercules, CA) heated to $42^{\circ} \mathrm{C}$.

Statistical analysis of gas production data at each time point, and VFA concentrations and $\mathrm{pH}$ in the in 


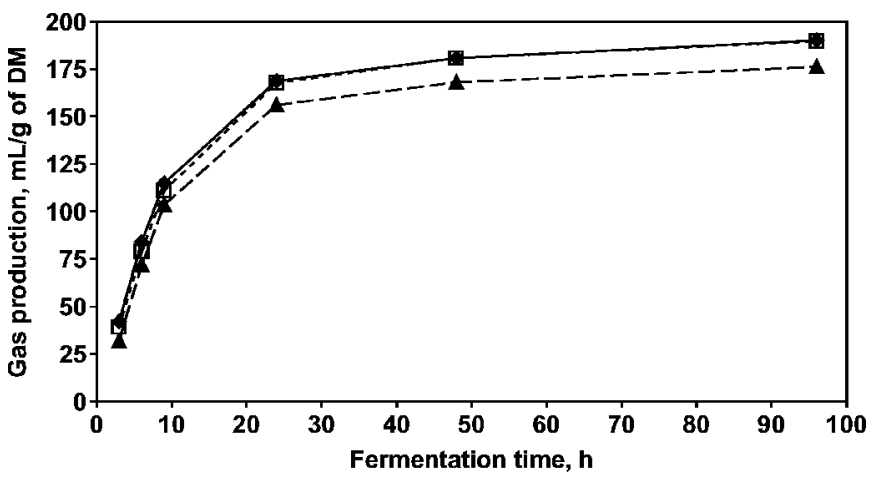

Figure 1. In vitro gas production with time in 3 treatments of first-cut alfalfa silage. Control ( $\bullet$; Enterococcus faecium C (highest inoculant treatment, $\square$ ); Lactobacillus plantarum, Agri-King (lowest inoculant treatment, $\mathbf{\Delta}$ ).

vitro fluid at $96 \mathrm{~h}$ was performed for each cut separately with PROC MIXED of SAS (SAS Inst. Inc., Cary, NC), with treatment and in vitro run as class variables, silo within treatment as a random variable, and treatment by in vitro run as a one-way interaction. Differences among means were tested by using the LSMEANS statement with the PDIFF option, and significance was declared at $P<0.10$.

For each cutting, a correlation analysis was performed with PROC CORR in SAS to determine whether any silage constituents [fiber concentrations, CP, water-soluble carbohydrates (WSC), $\mathrm{pH}$, silage fermentation products, IVTDMD] were correlated with gas production at 9 and $96 \mathrm{~h}$, relative gas production at $9 \mathrm{~h}$, and VFA production at $96 \mathrm{~h}$ (acetic acid, propionic acid, total VFA, acetate:propionate ratio). Significance was declared at $P<0.10$.

\section{RESULTS}

\section{In Vitro Gas Production}

Across both cuts, there was no consistent difference between fresh and frozen silages in in vitro fermentation, so the following results are presented as the average of the 3 in vitro runs in both trials. The rate of in vitro gas production was constant over the first $6 \mathrm{~h}$ and did not begin to decrease until nearly $9 \mathrm{~h}$ (Figure 1). Approximately half the gas production occurred in the first $6 \mathrm{~h}$. In first-cut silage, the $50 \%$ mark occurred after $6 \mathrm{~h}$ (Figure 1), whereas in second-cut silage, the $50 \%$ mark occurred slightly before $6 \mathrm{~h}$.

Gas production values for all treatments and time points in first-cut silage are shown in Table 2. Gas production was significantly $(P<0.10)$ affected by inoculant treatment at all times except at $48 \mathrm{~h}(P=0.132)$. The highest gas production occurred in the untreated control. Gas production values in the L. buchneri treatments were lower $(P<0.10)$ than those in the control for the first $9 \mathrm{~h}$, but not thereafter. Similarly, gas production for the first $9 \mathrm{~h}$ in the 6 commercial homofermentative treatments was significantly lower than that in the control treatment, with the exception of $\mathrm{H} / \mathrm{M}$ Plus. At $24 \mathrm{~h}$ and beyond, only 2 of the 6 treatments (Biomax5 and Biotal Plus) had significantly lower gas production than the control treatment. Gas production relative to the control varied considerably among the single strains. The lowest gas production occurred with the Agri-King L. plantarum and Lactobacillus pentosus, and their production was always lower than the control treatment, except at $48 \mathrm{~h}$. Conversely, E. faecium $\mathrm{C}$ and Ecosyl's Pediococcus pentosaceus had gas production similar to the control treatment throughout in vitro incubation.

Table 2. In vitro gas production $(\mathrm{mL} / \mathrm{g}$ of $\mathrm{DM})$ at various incubation times from the first-cut alfalfa silages

\begin{tabular}{|c|c|c|c|c|c|c|}
\hline Treatment & $3 \mathrm{~h}$ & $6 \mathrm{~h}$ & $9 \mathrm{~h}$ & $24 \mathrm{~h}$ & $48 \mathrm{~h}$ & $96 \mathrm{~h}$ \\
\hline Lactobacillus buchneri (Pioneer 11A44) & 34.3 & 73.6 & 105.8 & 164.1 & 176.9 & 185.9 \\
\hline L. buchneri (Biotal) & 36.3 & 75.8 & 108.3 & 166.2 & 179.0 & 187.6 \\
\hline L. plantarum and Pediococcus cerevisiae (Biomate LP/PC) & 36.7 & 77.1 & 108.0 & 163.7 & 176.4 & 185.9 \\
\hline L. plantarum (Biomax5) & 34.7 & 75.1 & 105.7 & 159.2 & 171.8 & 181.6 \\
\hline Pediococcus pentosaceus and Propionibacterium jensenii (Biotal Plus) & 36.2 & 75.5 & 105.5 & 157.7 & 169.6 & 178.1 \\
\hline E. faecium $\mathrm{C}$ (Agri-King) & 39.1 & 78.8 & 110.9 & 167.6 & 180.9 & 189.6 \\
\hline E. faecium $Q$ (Agri-King) & 33.7 & 73.2 & 105.0 & 163.0 & 175.9 & 184.9 \\
\hline Lactobacillus pentosus (Agri-King) & 32.8 & 69.5 & 99.4 & 155.9 & 168.7 & 177.9 \\
\hline L. plantarum (Agri-King) & 31.8 & 71.9 & 103.5 & 156.0 & 168.0 & 176.1 \\
\hline P. pentosaceus (Agri-King) & 36.7 & 77.8 & 108.4 & 162.7 & 174.9 & 184.3 \\
\hline P. pentosaceus (Ecosyl) & 37.5 & 78.7 & 110.7 & 166.8 & 179.5 & 189.2 \\
\hline $\operatorname{LSD}(P<0.10)$ & 4.51 & 6.25 & 6.63 & 7.44 & NS & 7.68 \\
\hline
\end{tabular}


Table 3. In vitro gas production $(\mathrm{ml} / \mathrm{g}$ of $\mathrm{DM})$ at various incubation times from the second-cut alfalfa silages

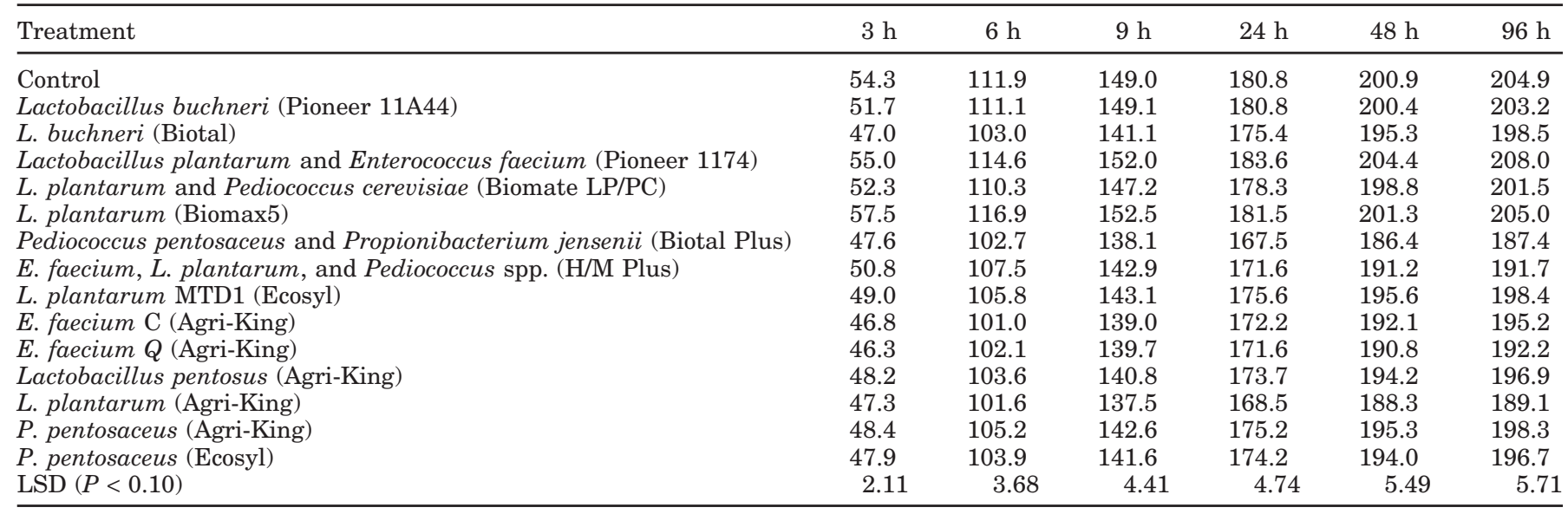

Gas production levels in the second-cut alfalfa silages are shown in Table 3 . Treatment significantly affected gas production at all time points $(P<0.01)$. The control treatment produced one of the highest levels of gas production. However, 2 treatments (Pioneer 1174 and Biomax5) consistently had higher rates of gas production, although the differences from the control were not statistically significant, except at 3 and $6 \mathrm{~h}$ for Biomax 5 . The other 4 commercial homofermentative inoculant treatments generally produced less gas than the control treatment across all time points. Similarly, the single homofermentative strains produced less gas than the control. One L. buchneri treatment (Biotal) consistently produced less gas than the control, whereas the other (Pioneer 11A44) had gas production similar to the control treatment, except at $3 \mathrm{~h}$.

\section{Relative Gas Production}

Relative gas production for each in vitro bottle was calculated by dividing gas production at a given time by the gas production for that bottle at $96 \mathrm{~h}$ to determine whether the relative rate of gas production was affected by treatment. In first-cut silage, the relative rate of gas production was significantly affected by treatment over the first $9 \mathrm{~h}$, with the fastest rate occurring in the control (Table 4). In the control treatment, 22, 44, and $60 \%$ of 96 -h gas production occurred by 3,6 , and $9 \mathrm{~h}$, respectively. The only treatments for which the relative rate of gas production was not significantly lower than that of the control for all 3 time points $(3,6,9 \mathrm{~h})$ were Biotal Plus, H/M Plus, and Agri-King's L. plantarum and $P$. pentosaceus. At 24 and $48 \mathrm{~h}$, the relative rate of

Table 4. Relative in vitro gas production (fraction of 96 -h production) at various incubation times from the first-cut alfalfa silages

\begin{tabular}{|c|c|c|c|c|c|}
\hline Treatment & $3 \mathrm{~h}$ & $6 \mathrm{~h}$ & $9 \mathrm{~h}$ & $24 \mathrm{~h}$ & $48 \mathrm{~h}$ \\
\hline Lactobacillus buchneri (Pioneer 11A44) & 0.184 & 0.396 & 0.568 & 0.883 & 0.951 \\
\hline L. buchneri (Biotal) & 0.193 & 0.405 & 0.577 & 0.886 & 0.954 \\
\hline L. plantarum and Pediococcus cerevisiae (Biomate LP/PC) & 0.196 & 0.416 & 0.580 & 0.881 & 0.948 \\
\hline L. plantarum (Biomax5) & 0.187 & 0.410 & 0.578 & 0.875 & 0.944 \\
\hline Pediococcus pentosaceus and Propionibacterium jensenii (Biotal Plus) & 0.203 & 0.424 & 0.592 & 0.886 & 0.951 \\
\hline E. faecium C (Agri-King) & 0.206 & 0.417 & 0.584 & 0.884 & 0.953 \\
\hline E. faecium $Q$ (Agri-King) & 0.182 & 0.397 & 0.567 & 0.882 & 0.951 \\
\hline Lactobacillus pentosus (Agri-King) & 0.183 & 0.390 & 0.557 & 0.875 & 0.947 \\
\hline L. plantarum (Agri-King) & 0.179 & 0.407 & 0.587 & 0.886 & 0.953 \\
\hline P. pentosaceus (Ägri-King) & 0.198 & 0.423 & 0.588 & 0.883 & 0.948 \\
\hline P. pentosaceus (Ecosyl) & 0.197 & 0.416 & 0.583 & 0.881 & 0.947 \\
\hline $\operatorname{LSD}(P<0.10)$ & 0.0196 & 0.0209 & 0.0167 & NS & NS \\
\hline
\end{tabular}


Table 5. Relative in vitro gas production (fraction of 96 -h production) at various incubation times from the second-cut alfalfa silages

\begin{tabular}{|c|c|c|c|c|c|}
\hline Treatment & $3 \mathrm{~h}$ & $6 \mathrm{~h}$ & $9 \mathrm{~h}$ & $24 \mathrm{~h}$ & $48 \mathrm{~h}$ \\
\hline Control & 0.261 & 0.548 & 0.728 & 0.884 & 0.981 \\
\hline Lactobacillus buchneri (Pioneer 11A44) & 0.252 & 0.548 & 0.734 & 0.890 & 0.986 \\
\hline L. buchneri (Biotal) & 0.235 & 0.520 & 0.711 & 0.884 & 0.983 \\
\hline L. plantarum and Pediococcus cerevisiae (Biomate LP/PC) & 0.258 & 0.548 & 0.730 & 0.885 & 0.985 \\
\hline L. plantarum (Biomax5) & 0.276 & 0.572 & 0.745 & 0.887 & 0.983 \\
\hline Pediococcus pentosaceus and Propionibacterium jensenii (Biotal Plus) & 0.254 & 0.549 & 0.737 & 0.894 & 0.995 \\
\hline E. faecium, L. plantarum, and Pediococcus spp. (H/M Plus) & 0.265 & 0.562 & 0.746 & 0.896 & 0.998 \\
\hline E. faecium $Q$ (Agri-King) & 0.238 & 0.531 & 0.726 & 0.892 & 0.991 \\
\hline Lactobacillus pentosus (Agri-King) & 0.244 & 0.528 & 0.716 & 0.883 & 0.986 \\
\hline L. plantarum (Agri-King) & 0.250 & 0.539 & 0.728 & 0.892 & 0.996 \\
\hline P. pentosaceus (Agri-King) & 0.241 & 0.530 & 0.719 & 0.884 & 0.984 \\
\hline P. pentosaceus (Ecosyl) & 0.241 & 0.528 & 0.720 & 0.886 & 0.985 \\
\hline $\operatorname{LSD}(P<0.10)$ & 0.0073 & 0.0099 & 0.0084 & NS & NS \\
\hline
\end{tabular}

gas production was not significantly affected by inoculant treatment.

In second-cut silage, relative gas production was significantly affected by treatment at the early time points (Table 5). In this cutting, 2 treatments (Biomax5 and $\mathrm{H} / \mathrm{M}$ Plus) had faster relative rates of gas production than the control treatment over the first $9 \mathrm{~h}$. At $3 \mathrm{~h}$, both L. buchneri treatments, Ecosyl's MTD1, and the 6 single homofermentative strain treatments had slower relative gas production than the control treatment. As incubation time increased, fewer treatments were significantly slower than the control treatment, until none was significantly below the control at 24 and $48 \mathrm{~h}$.

The fraction of gas remaining to be produced (i.e., 1.000 minus relative gas production) was plotted against fermentation time on a semilog plot to determine whether the rate of gas production declined with time in a first-order manner. The plots were linear for the first $24 \mathrm{~h}$ in the first-cut silage and only for the first $9 \mathrm{~h}$ in the second cut. Within a cut, the rate of decline for the early portion of in vitro fermentation was not significantly affected by treatment $(P>0.10)$. The average rate was 0.090 and $0.168 / \mathrm{h}$ for first- and secondcut silage, respectively.

\section{In Vitro Fermentation Products}

In first-cut silage, $\mathrm{pH}$ at the end of fermentation was unaffected by treatment (Table 6$)$. Acetic $(P<0.01)$ and propionic $(P<0.06)$ acid concentrations were affected by treatment, but butyric acid concentration was not. The control treatment had one of the highest acetic acid concentrations numerically but was not significantly different from 6 of the 8 commercial inoculants; Biomate and MTD1 were lower $(P<0.01)$. The 6 single strains all had lower acetic acid concentrations than did the control treatment. In contrast, the control treat- ment numerically had one of the lowest propionic acid concentrations, but only 3 treatments (Pioneer 1174, Biotal L. buchneri, and Biomax5) were significantly higher than the control $(P<0.05)$. Total VFA concentrations in the control treatment appeared numerically in the middle of the group of treatments. No treatment produced significantly higher total VFA concentrations, but 5 treatments (Biomate, MTD1, and Agri-King's $E$. faecium $\mathrm{C}$, L. plantarum, and P. pentosaceus) produced significantly less total VFA than the control. The control treatment had the highest acetate:propionate ratio, and only one treatment (Pioneer 11A44) was not significantly lower than the control.

In second-cut silage, the final $\mathrm{pH}$ of the in vitro fermentation was not affected by treatment (Table 7). As in first-cut silage, acetic acid, propionic acid, total VFA, and the acetate:propionate ratio were affected by treatment, whereas butyric acid was not. Acetic acid production in the control treatment was numerically in the middle of the values for the other treatments. Only Agri-King's P. pentosaceus was lower than the control treatment, and 2 treatments (Biomate and Pioneer 11A44) were higher than the control. The control treatment had one of the lowest propionic acid concentrations. However, only the 2 L. buchneri treatments, plus the Biomate and Pioneer 1174 treatments had significantly higher propionic acid concentrations. The control treatment had a total VFA concentration similar to those of most treatments; only Biomate and Biotal $L$. buchneri had higher total VFA concentrations. The acetate:propionate ratio in the control was the second highest numerically, but significant differences $(P<0.10)$ from the control in the acetate:propionate ratio (all lower) were found in only 7 treatments (Biomax5, both Biotal treatments, Agri-King's E. faecium C, L. pentosus, L. plantarum, and P. pentosaceus). 
Table 6. Characteristics of the $96-\mathrm{h}$ in vitro fluid from the first-cut alfalfa silages

\begin{tabular}{|c|c|c|c|c|c|c|}
\hline Treatment & $\mathrm{pH}$ & $\begin{array}{l}\text { Acetate, } \\
\mathrm{m} M\end{array}$ & $\begin{array}{c}\text { Propionate, } \\
\mathrm{m} M\end{array}$ & $\begin{array}{l}\text { Butyrate, } \\
\text { m } M\end{array}$ & $\begin{array}{l}\text { Total VFA, } \\
\mathrm{m} M\end{array}$ & $\begin{array}{l}\text { Acetate: } \\
\text { propionate }\end{array}$ \\
\hline Control & 6.25 & 53.3 & 21.1 & 8.2 & 82.6 & 2.57 \\
\hline Lactobacillus buchneri (Pioneer 11A44) & 6.27 & 54.4 & 22.1 & 8.3 & 84.8 & 2.50 \\
\hline Lactobacillus plantarum and Enterococcus faecium (Pioneer 1174) & 6.27 & 53.2 & 22.9 & 8.6 & 84.7 & 2.35 \\
\hline L. plantarum and Pediococcus cerevisiae (Biomate LP/PC) & 6.29 & 46.9 & 22.2 & 8.0 & 76.9 & 2.09 \\
\hline L. plantarum (Biomax5) & 6.25 & 52.2 & 23.4 & 8.3 & 83.9 & 2.26 \\
\hline Pediococcus pentosaceus and Propionibacterium jensenii (Biotal Plus) & 6.27 & 50.9 & 21.7 & 8.7 & 81.2 & 2.37 \\
\hline E. faecium C (Agri-King) & 6.29 & 47.9 & 20.6 & 7.9 & 76.5 & 2.32 \\
\hline E. faecium $Q$ (Agri-King) & 6.29 & 48.6 & 22.5 & 8.2 & 79.3 & 2.17 \\
\hline Lactobacillus pentosus (Agri-King) & 6.29 & 49.4 & 21.7 & 8.3 & 79.4 & 2.34 \\
\hline L. plantarum (Agri-King) & 6.29 & 48.2 & 21.3 & 7.8 & 77.3 & 2.27 \\
\hline P. pentosaceus (Agri-King) & 6.30 & 47.2 & 21.3 & 7.9 & 76.5 & 2.22 \\
\hline P. pentosaceus (Ecosyl) & 6.28 & 48.1 & 21.4 & 8.1 & 77.6 & 2.27 \\
\hline LSD $(P<0.10)$ & NS & 3.29 & 1.54 & NS & 5.19 & 0.125 \\
\hline
\end{tabular}

\section{Correlation Between In Vitro Fermentation and Silage Constituents}

The constituents significantly correlated with 9 - and 96-h gas production were not consistent between the 2 cuts. In first-cut silage, WSC $(r=0.780)$ was the only constituent highly correlated $(P<0.05)$ with 9 -h gas production, whereas in second-cut silage, 5 constituents were significant: CP (-0.719), IVTDMD (0.679), acid detergent lignin (0.592), cellulose (0.574), and WSC $(-0.523)$. Although WSC was significant in both cuts, the correlation was positive in first-cut silage and negative in second cut. At $96 \mathrm{~h}$, silage $\mathrm{pH}$ (0.569) and lactic acid $(-0.529)$ were more closely correlated with gas production than was WSC $(0.471, P=0.076)$ in first-cut silage. In second-cut silage, 96 -h gas production was strongly correlated with the same 5 constituents as at $9 \mathrm{~h}$, as well as with hemicellulose (0.572) and succinic acid (0.551).
The proportion of total gas production at $9 \mathrm{~h}$ was correlated with 2 constituents in both cuts: acetic acid $(-0.708,-0.630)$ and IVTDMD $(0.462,0.478)$. Additional significantly correlated components were WSC (0.571) and succinic acid (-0.570) in first-cut silage and silage $\mathrm{pH}(-0.571)$ in second-cut silage.

In vitro fermentation products (individual and total VFA) were generally poorly correlated with silage constituents. In vitro acetic acid and total VFA were not significantly $(P>0.05)$ correlated with any factor. The only closely correlated factors were IVTDMD with total VFA $(P=0.056 ; \mathrm{r}=-0.504)$. In contrast, in vitro propionic acid was correlated with various factors, but the significant factors differed between cuts. In first-cut silage, cellulose $(\mathrm{r}=0.639)$, NDF (0.622), ADF (0.597), and IVTDMD (-0.584) were significantly correlated with propionic acid. In second-cut silage, WSC (-0.721), silage $\mathrm{pH}(0.559)$, lactic acid (-0.558), acetic acid

Table 7. Characteristics of the 96 -h in vitro fluid from the second-cut alfalfa silages

\begin{tabular}{|c|c|c|c|c|c|c|}
\hline Treatment & $\mathrm{pH}$ & $\begin{array}{c}\text { Acetate, } \\
\mathrm{m} M\end{array}$ & $\begin{array}{c}\text { Propionate, } \\
\mathrm{m} M\end{array}$ & $\begin{array}{c}\text { Butyrate, } \\
\text { m } M\end{array}$ & $\begin{array}{l}\text { Total VFA, } \\
\mathrm{m} M\end{array}$ & $\begin{array}{l}\text { Acetate: } \\
\text { propionate }\end{array}$ \\
\hline Control & 6.37 & 42.8 & 16.8 & 8.2 & 67.8 & 2.62 \\
\hline Lactobacillus buchneri (Pioneer 11A44) & 6.34 & 45.6 & 18.1 & 7.5 & 71.3 & 2.57 \\
\hline Lactobacillus plantarum and Enterococcus faecium (Pioneer 1174) & 6.35 & 43.5 & 17.9 & 8.4 & 69.8 & 2.48 \\
\hline L. plantarum and Pediococcus cerevisiae (Biomate LP/PC) & 6.34 & 46.4 & 18.7 & 8.6 & 73.6 & 2.50 \\
\hline L. plantarum (Biomax5) & 6.37 & 41.2 & 17.1 & 7.7 & 65.9 & 2.44 \\
\hline E. faecium C (Agri-King) & 6.33 & 41.4 & 17.1 & 8.0 & 66.5 & 2.42 \\
\hline E. faecium $Q$ (Agri-King) & 6.34 & 44.6 & 17.3 & 8.2 & 70.1 & 2.58 \\
\hline Lactobacillus pentosus (Agri-King) & 6.35 & 42.4 & 17.7 & 8.3 & 68.4 & 2.45 \\
\hline L. plantarum (Agri-King) & 6.35 & 40.6 & 16.6 & 8.0 & 65.2 & 2.46 \\
\hline P. pentosaceus (Agri-King) & 6.35 & 39.3 & 17.1 & 7.9 & 64.3 & 2.34 \\
\hline P. pentosaceus (Ecosyl) & 6.35 & 43.3 . & 17.0 & 7.9 & 68.2 & 2.55 \\
\hline
\end{tabular}


(0.513), and ethanol (0.525) were the most significant. The acetate:propionate ratio was correlated with silage $\mathrm{pH}(0.538)$ and lactic acid $(-0.535)$ in first-cut silage but was not significantly correlated with any factor in second-cut silage, although IVTDMD (0.467) was significant at $P=0.080$.

\section{DISCUSSION}

\section{Gas Production-First Cut}

In first-cut silage, all the inoculants but $E$. faecium $\mathrm{C}$ reduced silage $\mathrm{pH}$ relative to the untreated control (Filya et al., 2007), and the best inoculant (Biomax5) reduced $\mathrm{pH}$ by 0.75 compared with the control. With substantial effects on $\mathrm{pH}$, most of the inoculants produced higher levels of lactic acid than the control and, less consistently, various inoculants reduced acetic acid and ethanol compared with the control. With clear changes in silage fermentation, we anticipated improvement in rumen in vitro fermentation from the inoculated silages. However, traditional $48-\mathrm{h}$ in vitro analysis with freeze-dried silages indicated no significant differences in IVTDMD among treatments (Filya et al., 2007), although all but one of the commercial homofermentative inoculants had numerically higher IVTDMD concentrations than did the control.

Although 48-h IVTDMD was not significantly increased by inoculants, significant differences in in vitro ruminal gas and VFA production caused by inoculant treatment were observed with undried silages. The untreated control had the highest gas production, one of the highest concentrations of acetic acid, one of the lowest concentrations of propionic acid, total VFA near the middle, and the highest acetate:propionate ratio. This shift toward in vitro propionic acid production in the inoculated silages in this cut would be expected because of the elevated lactic acid levels in most of the inoculant treatments and the expectation that the primary in vitro end product of lactic acid fermentation is propionic acid (Sharp et al., 1994). The shift toward a propionic acid end product with the inoculated silages would also be expected to reduce gas production (Wolin, 1960).

One can check whether the reduced gas production observed in the inoculated silages would be expected by using Wolin's equations and the measured VFA concentrations from the in vitro fermentations. Predictions of gas production from carbonate-buffered in vitro fermentations must also include the evolution of additional $\mathrm{CO}_{2}$ gas emitted on a 1:1 molar basis proportional to VFA production (Blümmel et al., 1997). Accounting for these sources of gas production, the untreated control would have been expected to produce $236 \mathrm{~mL} / \mathrm{g}$ of DM. This is higher than the amount observed $(190 \mathrm{~mL} /$

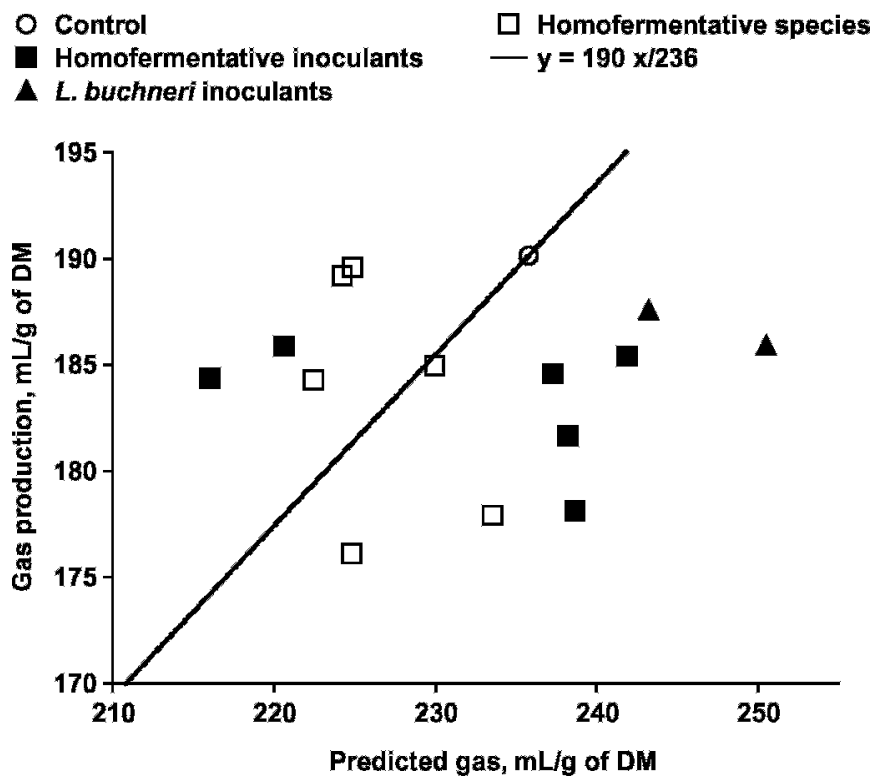

Figure 2. In vitro gas production at $96 \mathrm{~h}$ for first-cut alfalfa silages as correlated with predicted gas production based on in vitro fermentation products according to Blümmel et al. (1997). The line assumes the same ratio between actual and predicted gas production as observed for the control silage.

g of DM) but was not unreasonable. The pressure in the sealed in vitro bottles will reduce gas volume as more methane and, in particular, $\mathrm{CO}_{2}$ go into solution. That would reduce the predicted gas volume by approximately $20 \mathrm{~mL} / \mathrm{g}$ of DM under our experimental conditions. In addition, Wolin's gas production equations consider only the fermentation of carbohydrates, not a more complex substrate such as alfalfa silage.

Predicted gas production is compared with actual gas production for all 15 treatments in Figure 2. Based on in vitro VFA production, more gas should have been produced by 4 of the 6 commercial homofermentative inoculant-treated silages and by both L. buchneritreated silages than the untreated control silage. Furthermore, if one assumes that actual-to-predicted gas production is in the same proportion as observed for the control (the line in Figure 2), then the silages from 2 of the homofermentative single strains produced substantially less gas than predicted. In addition, 5 treatments were predicted to produce less gas than the control treatment, but the actual level of reduction was less than predicted. All but 1 of the 5 treatments had IVTDMD concentrations numerically higher than the control.

\section{Gas Production-Second Cut}

The second-cut trial provided a greater challenge for the inoculant LAB. The epiphytic LAB population was 
O Control

Homofermentative inoculants

A L. buchneri inoculants

$\square$ Homofermentative species

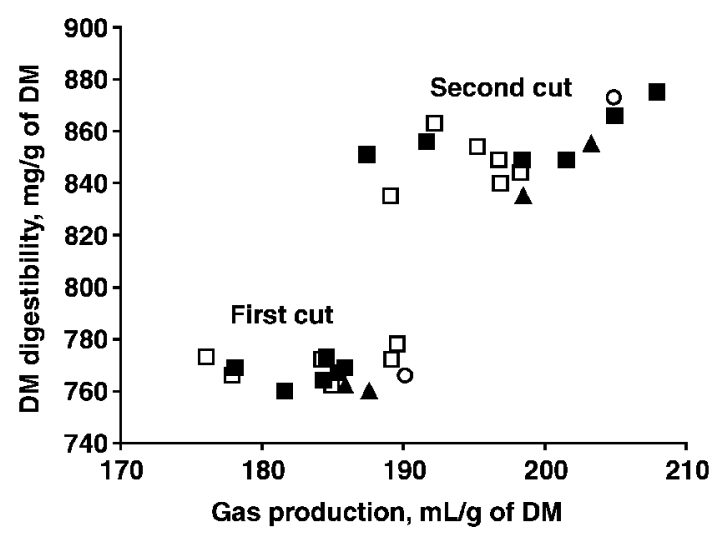

Figure 3. In vitro true DM digestibility of freeze-dried silages as compared with in vitro gas production at $96 \mathrm{~h}$ on undried samples of the same silages.

more than 10 times the application rates of the inoculant LAB. In addition, the uninoculated silage achieved a low $\mathrm{pH}(4.42)$ with a high lactic acid content ( $86.5 \mathrm{~g} /$ $\mathrm{kg}$ of DM). Even with these challenges, all 8 of the commercial inoculant products produced significant shifts in $\mathrm{pH}$ or fermentation products, indicating that they had affected the final outcome of silage fermentation (Filya et al., 2007). The 6 homofermentative single strains showed less evidence of affecting fermentation. Although the levels of fermentation products were statistically different among treatments, the magnitudes of the differences were smaller than in the first-cut silages, so one might expect differences among treatments in in vitro fermentation to be less likely. However, IVTDMD was highest in Pioneer 1174 and the control treatment, and 8 treatments had significantly lower IVTDMD than the control treatment.

In this cut, gas production from the in vitro fermentation of the undried silages was correlated with the IVTDMD measurements from the freeze-dried silages ( $\mathrm{r}=0.679$ and 0.532 for 9 and $96 \mathrm{~h}$, respectively). The highest gas production at 48 and $96 \mathrm{~h}$ occurred in the Pioneer 1174, control, and Biomax5 silages, the silages with the highest IVTDMD concentrations. However, the treatments with the lowest IVTDMD concentrations did not necessarily produce the lowest amounts of gas (Figure 3).

Although gas production appeared to parallel IVTDMD in second-cut silage, the VFA pattern was somewhat unexpected. The acetate:propionate ratio was high in the control silage; only the value for $\mathrm{H} / \mathrm{M}$ Plus was numerically higher. This occurred even though the control silage had the highest lactic acid

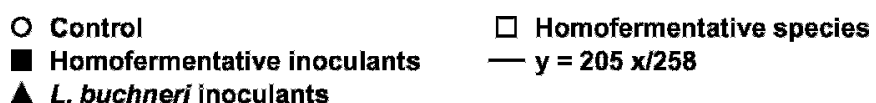

$\Delta$ L. buchneri İnoculants

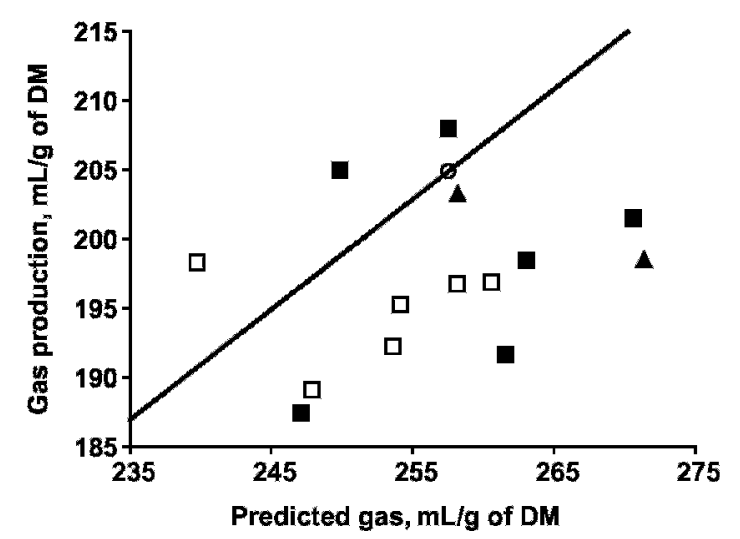

Figure 4. In vitro gas production at $96 \mathrm{~h}$ for second-cut alfalfa silages as correlated with predicted gas production based on in vitro fermentation products according to Blümmel et al. (1997). The line assumes the same ratio between actual and predicted gas production as observed for the control silage.

concentration (Filya et al., 2007). The levels of acetic acid, butyric acid, and total VFA produced in vitro by the control silages were in the middle of the 15 treatments rather than near the top, as might be expected by the IVTDMD values. In addition, across the 15 treatments, VFA production (either total or individual acids) was not correlated with IVTDMD, although there was a positive correlation with the acetate:propionate ratio.

The poor correlations between IVTDMD of freezedried silages and the various in vitro gas and VFA measurements made on wet silages may be attributable to a number of causes. They are most likely due to the differences between using a dried vs. wet silage, as suggested by the results of Calabrò et al. (2001) and Lee et al. (2002). However, differences among batches of rumen fluid could also have affected the results. In retrospect, comparisons between in vitro methods would have been more meaningful if DM disappearance had been measured at $96 \mathrm{~h}$ in the in vitro analyses of the wet silages.

As for first-cut silage, we predicted gas production at $96 \mathrm{~h}$ based on the amounts of VFA produced during in vitro fermentation (Figure 4). By these calculations, 8 of the treatments should have produced more gas than the control, as contrasted with one observed treatment. If one assumes that actual gas production is in the same proportion to predicted gas production as observed for the control (the line in Figure 4), then 10 inoculated treatments produced substantially less gas than expected, based on the control treatment. The 2 commercial inoculants with higher than predicted gas produc- 
tion (above the line) were Pioneer 1174 and Biomax5, the 2 with the highest IVTDMD concentrations of the inoculated treatments.

\section{Inoculant Effects on In Vitro Ruminal Fermentation}

Weinberg et al. (2003) showed that many of the same LAB used in the current study could survive in strained rumen fluid for $72 \mathrm{~h}$. Furthermore, some of the added inoculant bacteria kept the in vitro rumen fluid $\mathrm{pH}$ higher than that of uninoculated rumen fluid. These results suggest that LAB from silage have the potential to influence the rumen environment.

In the current study, various inoculant bacteria affected silage fermentation considerably in first-cut silage and, to a more limited degree, in second-cut silage (Filya et al., 2007). However, there were no significant positive effects on IVTDMD from inoculation in either trial. When the undried silages were incubated in rumen fluid, the in vitro analyses suggested that the inoculants were having an unanticipated effect on in vitro fermentation. In both trials, despite whether substantial changes in silage fermentation occurred, the untreated control silages produced in vitro rumen fermentation with one of the highest levels of gas production per unit of silage fermented and the highest acetate:propionate ratios. In first-cut silage, this might be explained by the low lactic acid concentration in the control silages. However, in second-cut silage, the control silages had the highest lactic acid concentrations. Moreover, the majority of inoculated silages in both trials had less gas production relative to the control silages than was predicted from in vitro VFA production. Blümmel et al. (1997) indicated that as in vitro gas production per unit of substrate truly degraded decreased, microbial biomass per unit of substrate truly degraded increased. Our results did not permit calculation of gas production on this basis, but in both trials gas production was reduced by up to $7 \%$ in an inoculated treatment relative to the control, whereas the biggest effect on IVTDMD relative to the control was 1.6 in first-cut silage and $4.4 \%$ in second cut. These results suggest that some inoculated silages may be producing more microbial yield than the control silages during in vitro rumen fermentation. If this were true, this could help to explain why some inoculated silages improve animal performance.

\section{CONCLUSIONS}

In 2 trials comparing the in vitro ruminal fermentation of wet-ground silages, the silages treated with inoculants generally produced, or tended to produce, less in vitro gas per unit of $\mathrm{DM}$ incubated than the control silages, despite whether silage fermentation was affected substantially by inoculation with LAB. The in vitro fermented wet control silages had one of the highest acetate:propionate ratios in both trials, even though the control silage was highest in lactic acid in one trial and lowest in the other. Overall, inoculation of crops at ensiling with $\mathrm{LAB}$ appeared to affect in vitro rumen fermentation of wet-ground silages, even in the absence of large effects during silage fermentation or in the absence of effects on in vitro digestibility of dried silages. This suggests that more research is needed to uncover how inoculant LAB influence rumen fermentation.

\section{ACKNOWLEDGMENTS}

The authors are grateful for the technical assistance of U. C. Hymes-Fecht and help with analyses from S. Coleman.

\section{REFERENCES}

Blümmel, M., H. P. S. Makkar, and K. Becker. 1997. In vitro gas production: A technique revisited. J. Anim. Physiol. Anim. Nutr. (Berl.) 77:24-34.

Calabrò, S., F. Infascelli, F. Bovera, G. Moniello, and V. Piccolo. 2001. In vitro degradability of three forages: Fermentation kinetics and gas production of NDF and neutral detergent-soluble fraction of forages. J. Sci. Food Agric. 82:222-229.

Filya, I. 2003a. The effect of Lactobacillus buchneri and L. plantarum on the fermentation, aerobic stability, and ruminal degradability of low dry matter corn and sorghum silages. J. Dairy Sci. $86: 3575-3581$.

Filya, I. 2003b. The effect of Lactobacillus buchneri, with or without homofermentative lactic acid bacteria, on the fermentation, aerobic stability, and ruminal degradability of wheat, sorghum, and maize silages. J. Appl. Microbiol. 95:1080-1086.

Filya, I., R. E. Muck, and F. E. Contreras-Govea. 2007. Inoculant effects on alfalfa silage: Fermentation products and nutritive value. J. Dairy Sci. 90:5108-5114.

Goering, H. K., and P. J. Van Soest. 1970. Forage Fiber Analysis (Apparatus, Reagents, Procedures and Some Applications). Agric. Handbook No. 379. US Gov. Printing Off., Washington, DC.

Gordon, F. J. 1989. A further study of the evaluation through lactating cattle of a bacterial inoculant as an additive for grass silage. Grass Forage Sci. 44:353-357.

Kung, L., Jr., J. H. Chen, E. M. Creck, and K. Knusten. 1993. Effect of microbial inoculants on the nutritive value of corn silage for lactating dairy cows. J. Dairy Sci. 76:3763-3770.

Kung, L., Jr., and R. E. Muck. 1997. Animal response to silage additives. Pages 200-210 in Silage: Field to Feedbunk. NRAES-99. Northeast Reg. Agric. Eng. Serv., Ithaca, NY.

Kung, L., Jr., M. R. Stokes, and C. J. Lin. 2003. Silage additives. Pages 305-360 in Silage Science and Technology. D. R. Buxton, R. E. Muck, and J. H. Harrison, ed. Am. Soc. Agron., Crop Sci. Soc. Am., Soil Sci. Soc. Am., Madison, WI.

Lee, M. R. F., A. E. Brooks, J. M. Moorby, M. O. Humphreys, M. K. Theodorou, J. C. MacRae, and N. D. Scollan. 2002. In vitro investigation into the nutritive value of Lolium perenne bred for an elevated concentration of water-soluble carbohydrate and the added effect of sample processing: Freeze-dried and ground vs. frozen and thawed. Anim. Res. 51:269-277.

Muck, R. E., and J. T. Dickerson. 1988. Storage temperature effects on proteolysis in alfalfa silage. Trans. ASAE 31:1005-1009.

Rymer, C., A. R. Moss, E. R. Deaville, and D. I. Givens. 1998. Factors affecting the amount of indirect gas produced by the in vitro gas 
production technique. Pages 89-91 in In Vitro Techniques for Measuring Nutrient Supply to Ruminants. Occas. Publ. No. 22. E. R. Deavilee, E. Owen, A. T. Adesogan, C. Rymer, J. A. Huntington, and T. L. J. Lawrence, ed. Br. Soc. Anim. Sci., Edinburgh, UK.

Schofield, P., and A. N. Pell. 1995. Validity of using accumulated gas pressure readings to measure forage digestion in vitro: A comparison involving three forages. J. Dairy Sci. 78:2230-2238.

Sharp, R., P. G. Hooper, and D. G. Armstrong. 1994. The digestion of grass silages produced using inoculants of lactic acid bacteria. Grass Forage Sci. 49:42-53.

Steen, R. W. J., E. F. Unsworth, H. I. Gracey, S. J. Kennedy, R. Anderson, and D. J. Kilpatrick. 1989. Evaluation studies in the development of a commercial bacterial inoculant as an additive for grass silage. 3. Response in growing cattle and interaction with protein supplementation. Grass Forage Sci. 44:381-390.

Theodorou, M. K., B. A. Williams, M. S. Dhanoa, A. B. McAllan, and J. France. 1994. A simple gas production method using a pressure transducer to determine the fermentation kinetics of ruminant feeds. Anim. Feed Sci. Technol. 48:185-197.

Tilley, J. M. A., and R. A. Terry. 1963. A two-stage technique for the in vitro digestion of forage crops. J. Br. Grassl. Soc. 18:104-111.

Weimer, P. J., B. S. Dien, T. L. Springer, and K. P. Vogel. 2005. In vitro gas production as a surrogate measure of the fermentability of cellulosic biomass to ethanol. Appl. Microbiol. Biotechnol. 67:52-58.

Weinberg, Z. G., G. Ashbell, Y. Hen, A. Azrieli, G. Szakacs, and I. Filya. 2002. Ensiling whole-crop wheat and corn in large containers with Lactobacillus plantarum and Lactobacillus buchneri. J. Ind. Microbiol. Biotechnol. 28:7-11.

Weinberg, Z. G., and R. E. Muck. 1996. New trends in development and use of inoculants for silage. FEMS Microbiol. Rev. 19:53-68.

Weinberg, Z. G., R. E. Muck, and P. J. Weimer. 2003. The survival of silage inoculant lactic acid bacteria in rumen fluid. J. Appl. Microbiol. 94:1066-1071.

Wolin, M. J. 1960. A theoretical rumen fermentation balance. J. Dairy Sci. 43:1452-1459. 